\title{
Evaluation of noise hazard during the holmium laser enucleation of prostate
}

\author{
Huan Xu', Yan-bo Chen ${ }^{\dagger}$, Meng Gu, Qi Chen ${ }^{*}$ and Zhong Wang ${ }^{*}$
}

\begin{abstract}
Background: To evaluate noise hazard during holmium laser enucleation of the prostate (HoLEP), we designed a study to detect such a risk in this procedure.

Methods: This study was conducted over a 12-month period on 223 patients with benign prostatic hyperplasia (BPH), 121 of whom underwent HoLEP while those remaining underwent transurethral resection of the prostate (TURP). A sound level meter was used to detect the exposure of surgeons to noise. The recordings used were in accordance with the standards set by the Occupational Safety and Health Administration (OSHA) and the United States Environmental Protection Agency. Moreover, each of the 43 surgeons participating in a BPH discussion conference answered the questionnaire on the influence of noise, and 33 surgeons in our department volunteered for blood pressure monitoring post-surgically.

Results: The sound level produced by a high-powered holmium laser emitter during HoLEP was $67.37 \pm 0.13 \mathrm{~dB}$, which was significantly higher than the sound heard during TURP (46.41 $\pm 0.29 \mathrm{~dB}, P<0.01)$. The 65-70 dB noise during HoLEP was proved to be a safe level in accordance with the OSHA standards. However, this level was considerably greater than the stated $55 \mathrm{~dB}$. Moreover, it exceeded the normal communication protective level of $60 \mathrm{~dB}$. In the analysis of responses from the surgeons, the HoLEP group obtained an average score that reflected disturbance caused by the laser emitter and an increase in average systolic pressure relative to that in the TURP group.

Conclusions: The noise level during HoLEP is within hearing conservation levels. However, the noise disturbs intrateam communication and concentration during surgery. Some surgeons may experience discomfort post-surgically , but no significant difference among the groups is indicated. The findings suggest that measures should be taken to address the noise caused by the laser emitter during HoLEP.
\end{abstract}

\section{Background}

With the development of minimally invasive surgery, holmium laser enucleation of prostate (HoLEP) has been widely used worldwide and is considered as the "new golden standard" for benign prostate hyperplasia (BPH) [1]. A large number of studies have focused on the effects of surgery on patients, but few have evaluated the effects of surgery on surgeons. One of the potential risks of surgery for doctors is noise exposure. To reduce the negative effects of noise hazard, national and European community directives as well as United Nations guidelines recommend a $55 \mathrm{db}$ threshold for work requiring concentration such as "decisions under time pressure," "decisions with

* Correspondence: qiqi_chenqi@yeah.net; zhongwang2000@sina.com ${ }^{\dagger}$ Equal contributors

Department of Urology, Shanghai 9th People's Hospital, Shanghai Jiaotong University School of Medicine, 639 Zhi Zaoju Road, Shanghai 200011, China severe consequences," or "examinations and operations by physicians, meetings, research, teaching." [2]. Ambient noise exhibits a tendency to affect performance during surgery, causing decreased concentration and mental loading during surgery; dexterity is also decreased, as shown in the simulation video [3, 4]. Noise volume is associated with surgical site infection, which may cause serious post-surgical complications [5]. In many medical areas, such as orthopedic and dental department, noise hazards have recently been reported and is given considerable attention $[6,7]$. The present study is the first to evaluate the influence of noise produced during HoLEP on urological surgeons.

\section{Methods}

This study was performed over a period of 12 months on 223 patients. Among the patients, 121 underwent 
HoLEP using a high-powered holmium laser with a $100 \mathrm{~W}$ continuous flow and with power settings of 80 $100 \mathrm{~W}$ at $2-1.5 \mathrm{~J} / \mathrm{s}$ and $50-40 \mathrm{~Hz}$. The remaining 102 patients underwent TURP. Average sound levels were recorded during surgery, and the sound range was measured during the procedure. The location chosen was $40 \mathrm{~cm}$ away from the surgeons' head. The sound level meter (Control Company, Friendswood, TX) produced by Thomas Scientific was used to measure the sound in decibels.

In addition, each of the 59 surgeons participating in a $\mathrm{BPH}$ operating conference responded to questionnaire regarding the effect of HoLEP noise on the performance of the surgeon, most of whom were skilled in both HoLEP and TURP. Excluding the incomplete questionnaires and those with logically erroneous responses, 43 of the 59 questionnaires were considered valid. The surgeons, aged 30-40 years, came from 4 different provinces in China. Among those participating in the HoLEP or TURP surgical procedures, 34 surgeons volunteered for blood pressure monitoring post-surgically. Ethical approval and written informed consent of the patients and the doctors were obtained.

All results obtained from the questionnaire were presented as means \pm S.E.M. Statistically significant differences were assessed by 1-way ANOVA. All statistical analyses were performed using SPSS ver. 17.0. $P$ value $\leq 0.05$ was considered statistically significant.

\section{Results}

As presented in Table 1, the sound level produced by the high-powered holmium laser emitter during HoLEP is greater than that produced during TURP $(67.37 \pm 0.13 \mathrm{~dB}$ VS. $46.41 \pm 0.29 \mathrm{~dB}, P<0.01)$. The sound level produced during HoLEP against time is shown in Fig. 1. The harsh noise coming from the anesthesia alarm was $64.71 \pm 0.73 \mathrm{~dB}$, which is close to $67 \mathrm{~dB}$. The sound during TURP was $46.41 \pm 0.29 \mathrm{~dB}$, which is close to the baseline at $45.38 \pm 0.35 \mathrm{~dB}$. The noise range of 65-70 $\mathrm{dB}$ during HoLEP verified the safety standard set by the Occupational Safety and Health Administration (OSHA), which allows $8 \mathrm{~h}$ of exposure to $90 \mathrm{~dB}$ per day. However, $65-70 \mathrm{~dB}$ was considerably louder than the stated $55 \mathrm{~dB}$ for work

Table 1 Sound level measurements

\begin{tabular}{llll}
\hline Sound source & $\begin{array}{l}\text { Average sound level } \\
(\mathrm{dB}) \pm \text { S.E.M. }\end{array}$ & $\begin{array}{l}\text { Sound range } \\
(\mathrm{dB})\end{array}$ & $P$ value \\
\hline HoLEP & $67.37 \pm 0.13$ & $65.00-70.00$ & \\
TURP & $46.41 \pm 0.29$ & $42.10-51.82$ & $<0.01$ \\
Anesthesia alarm & $64.71 \pm 0.73$ & $63.07-69.31$ & 0.73 \\
Base Line & $45.38 \pm 0.35$ & $44.21-49.76$ & $<0.01$ \\
\hline
\end{tabular}

requiring concentration. The range also exceeded the normal communication protective level of $60 \mathrm{~dB}$.

Analysis of the responses from the surgeons indicated that in the HoLEP group, the laser emitter caused disturbance. As presented in Table 2, the score for the question "How strong was the disturbance of your communication/ concentration by noise?" was significantly higher in the HoLEP group than in the TURP group; however, no significant difference in hearing function damage was found between the 2 groups.

Analysis of results for systolic pressure (Table 3) indicated a slight increase in systolic pressure in the HoLEP group relative to that in the TURP group $(140.9 \pm 1.25$ vs. $134.89 \pm 1.01 \mathrm{mmHg}, P<0.01)$, whereas no significant difference was observed in the diastolic pressure results $(89.5 \pm 0.98$ VS. $88.4 \pm 1.67 \mathrm{mmHg}, P=0.562)$.

\section{Discussion}

Concern for the health of physicians has drawn increasing attention because of their high-pressure working environment. Noise during surgery negatively affects surgeons. However, studies on the noise levels produced by various surgical instruments have rarely been conducted. This study aims to evaluate the sound level during HoLEP. Thus, we determined whether the sound level in the operating room during surgery was hazardous to the surgeon. Our study confirmed that the noise produced by the high-powered holmium laser emitter, which falls within the range considered safe by OSHA, does not negatively affect the surgeons' audition in theory. Regardless, this matter should be given attention because the sound level beyond $60 \mathrm{~dB}$ is the upper threshold for normal communication, and $55 \mathrm{~dB}$ is the limit for "examinations and operations by physicians, meetings, research, and teaching."

The safe standard range set by OSHA is designed to measure sound health in various working areas. "Table G16 " by OSHA allows $8 \mathrm{~h}$ of exposure to $90 \mathrm{~dB}$ per day beyond which hearing protection is required [8]. Meanwhile, EPA and World Health Organization deliver the standard for normal communication and work requiring concentration [9]. The sound level within the range is comfortable for doctors in the operating room and similar professionals. As suggested, the ideal degree of loudness for normal communication is $45 \mathrm{~dB}$, and the maximum is $60 \mathrm{~dB}$.

As is known, noise exerts negative effects on surgeons and patients. Previous studies have reported on noise in the operating theater, which exerts deleterious effects $[2,6,10,11]$. Kurmann et al. used an intraoperative noise volume associated with subsequent surgical site infection in 35 elective open abdominal procedures [5]. In addition, the high level of noise significantly increased the incidence of postoperative complications [2]. These complications were partly attributed to the disturbance caused by the noise on the 


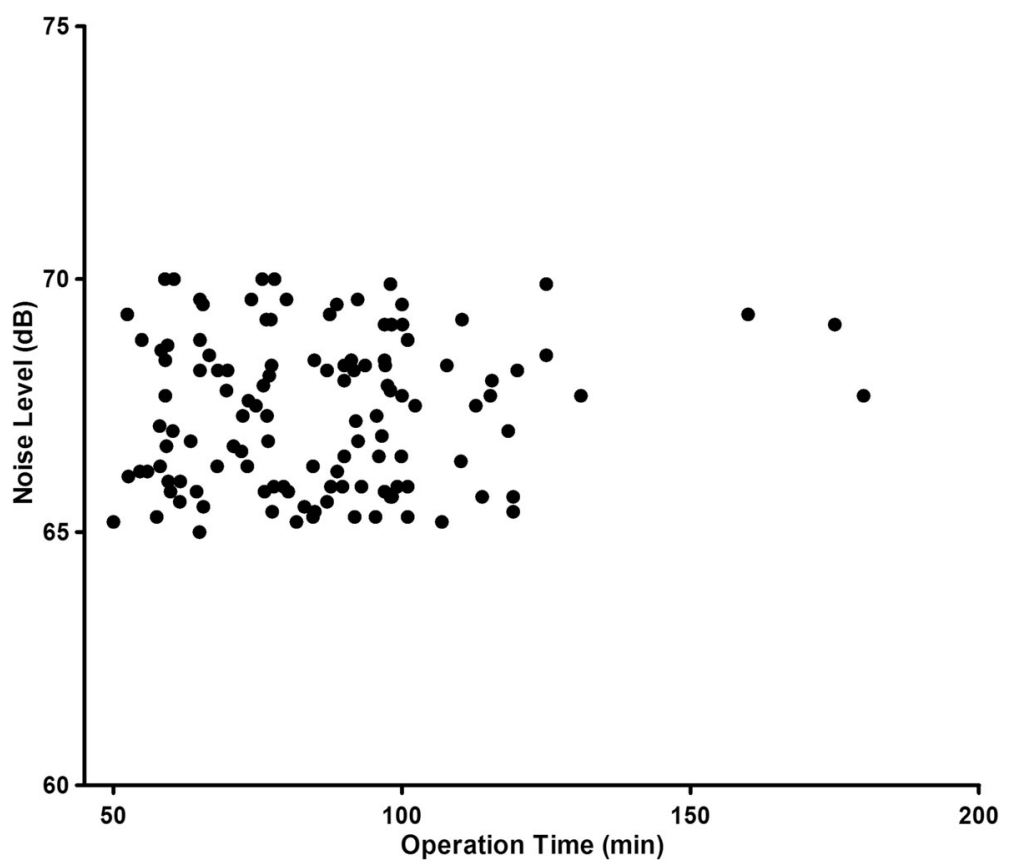

Fig. 1 Noise levels against time since HoLEP started

surgeon. A study found that surgeons surrounded by loud noise experienced decreased intrateam communication and interrupted conversations [2]. Another study reported that biometrically, the increased sound level enhanced both the pre- and post- operative cortisol levels and increased electrodermal potential in surgeons, which could be attributable to severe stress [12]. Thus, more effective technical and behavioral measures could be applied.

In urology, several studies suggested that the noise produced by extracorporeal shock wave lithotripsy (ESWL) can harm the hearing of the operating room personnel and the patient, although other studies contradicted this finding [13]. The difference between ESWL and the surgical procedure is that in the latter, concentration must be expended by surgeons into the surgery itself. The use of

Table 2 Investigation results and analysis

\begin{tabular}{lll}
\hline Question & \multicolumn{2}{l}{ Average score } \\
\cline { 2 - 3 } & HoLEP & TURP \\
\hline $\begin{array}{l}\text { How strong was the auditory threshold } \\
\text { up-regulated post-surgically? }\end{array}$ & $0.8 \pm 0.5$ & $0.0 \pm 0.0$ \\
$\begin{array}{l}\text { How strong was your sleep disorder or } \\
\text { dizziness? }\end{array}$ & $0.6 \pm 0.5$ & $0.0 \pm 0.0$ \\
$\begin{array}{l}\text { How strong was the disturbance of your } \\
\text { communication by noise? }\end{array}$ & $2.2 \pm 0.2^{\mathrm{a}}$ & $0.0 \pm 0.0$ \\
$\begin{array}{l}\text { How strong was the disturbance of your } \\
\text { concentration by noise? }\end{array}$ & $0.8 \pm 0.4^{\mathrm{a}}$ & $0.0 \pm 0.0$ \\
$\begin{array}{l}\text { How strong have you felt uncomfortable } \\
\text { after surgery because of the noise? }\end{array}$ & $0.8 \pm 0.5$ & $0.0 \pm 0.0$ \\
$\begin{array}{l}\text { a } P<0.05 \\
\end{array}$ & & \\
\hline
\end{tabular}

HoLEP in BHP has been increasingly prevalent because of its superior outcome and low risk of bleeding. HoLEP can potentially replace TURP as the new golden standard for $\mathrm{BPH}$ [1], but the noise caused by the laser emitter presents a problem. No studies have been reported on the subject; however many surgeons have complained about the upsetting side effects of the noise coming from the holmium laser emitter. To the best of our knowledge, this study is the first to report on the effect of noise produced during HoLEP on surgeons.

The results of our study showed that the baseline in the operating room was in the $45.38 \pm 0.35 \mathrm{~dB}$ range. The sound produced during TURP, which is set as the control, was in the $46.41 \pm 0.29 \mathrm{~dB}$ range. The noise levels produced during both procedures were considerably lower than the maximum noise for normal communication $(60 \mathrm{~dB})$. Although the noise of anesthesia alarm exceeded the normal communication threshold, it was transient and short-term. In the HoLEP group, the noise reached $70 \mathrm{~dB}$, and the average level was about $67.37 \pm 0.13 \mathrm{~dB}$. The reading near the surgeon's station verified the safety of the level of exposure set by OSHA standards, which

Table 3 Blood pressure of surgeons

\begin{tabular}{llcll}
\hline & SP $(\mathrm{mmHg}) \pm$ S.E.M & $P$ value & DP $(\mathrm{mmHg}) \pm$ S.E.M & $P$ value \\
\hline HoLEP & $140.9 \pm 1.25$ & & $89.5 \pm 0.98$ & \\
TURP & $134.89 \pm 1.01$ & $<0.01$ & $88.4 \pm 1.67$ & 0.562
\end{tabular}

SP systolic pressure, $D P$ diastolic pressure 
allows $8 \mathrm{~h}$ of exposure to $90 \mathrm{~dB}$ per day. For hearing conservation, the $67.37 \pm 0.13 \mathrm{~dB}$ level exhibited no tendency to reach the $75 \mathrm{~dB}$ level. Thus, no hearing hazard was observed during HoLEP. Normal communication was disturbed by the laser emitter, as determined in the study. The period lasting almost $60 \mathrm{~min}$ was filled with 65-70 dB noise; this degree of loudness was much higher than that by normal communication standards. During our 1-year study, 2 surgeons who performed 5 HoLEP procedures in a single day complained about tinnitus during sleep on the same day. The noise produced by the laser emitter was in the form of pulses and mainly came from the cooling system. Thus, the laser machine could be enhanced to avoid the noise.

This study has potential clinical implications. The noise level during HoLEP was within hearing conservation, but it disturbed intrateam communication and individual concentration during surgery. The noise produced by the laser emitter during HoLEP disturbed communication and concentration during surgery but did not affect hearing. In addition, post-surgical discomfort might be experienced. The major limitation of this study is its small sample size, which precludes multivariable analysis. Further studies should be conducted. Measures must also be taken to address the disturbance caused by HoLEP noise and to protect the surgeon.

\section{Conclusions}

The noise coming from the laser emitter during HoLEP disturbs intrateam communication and the concentration of surgeons working in the operating room; however, no hearing injury is detected. Some surgeons may also experience discomfort post-surgically. Measures must be taken to resolve the disturbance caused by the noise produced during HoLEP.

\section{Abbreviations}

BPH: Benign prostatic hyperplasia; EPA: Environmental protection agency; HoLEP: Holmium laser enucleation of the prostate; OSHA: Occupational Safety and Health Administration; TURP: Transurethral resection of the prostate

\section{Acknowledgements}

We gratefully acknowledge the urologists making great contributions to the prostatic enucleation, especially to Yinghao Sun and Peter Gilling. Authors' Information: Huan Xu, Yan-bo Chen, Meng Gu, Qi Chen, Zhong Wang. Department of Urology, Shanghai 9th People's Hospital, Shanghai Jiaotong University School of Medicine, Shanghai 200011, China.

\section{Funding}

Data collection and analysis: key disciplines group construction project of pudong health bureau of shanghai (PWZxq2014-11) and key project of science and technology of Shanghai (No. 134119a9800).

\section{Availability of data and materials}

The datasets during and/or analysed during the current study available from the corresponding author on reasonable request.

\section{Authors' contributions}

Study design: HX, ZW, QC, Data collection: YBC, data analysis: MG, HX, writing paper: HX. All authors read and approved the final manuscript.
Ethics approval and consent to participate

Ethical approval was obtained from the Ethics Committee in the 9th people's hospital in Shanghai and patient and doctor written informed consent was obtained in our study.

\section{Consent for publication}

All of the details can be published and consent for publication was not required for this study.

\section{Competing interests}

The authors declare that they have no competing interests.

\section{Publisher's Note}

Springer Nature remains neutral with regard to jurisdictional claims in published maps and institutional affiliations.

Received: 8 July 2016 Accepted: 6 July 2017

Published online: 31 August 2017

\section{References}

1. van Rij S, Gilling PJ. In 2013, holmium laser enucleation of the prostate (HoLEP) may be the new 'gold standard'. Curr Urol Rep. 2012;13(6):427-32.

2. Engelmann CR, Neis JP, Kirschbaum C, Grote G, Ure BM. A noise-reduction program in a pediatric operation theatre is associated with surgeon's benefits and a reduced rate of complications: a prospective controlled clinical trial. Ann Surg. 2014;259(5):1025-33.

3. Arora S, Sevdalis N, Nestel D, Woloshynowych M, Darzi A, Kneebone R. The impact of stress on surgical performance: a systematic review of the literature. Surgery. 2010;147(3):318-30. 330 e311-316.

4. Sevdalis N, Healey AN, Vincent CA. Distracting communications in the operating theatre. J Eval Clin Pract. 2007;13(3):390-4.

5. Kurmann A, Peter M, Tschan F, Muhlemann K, Candinas D, Beldi G. Adverse effect of noise in the operating theatre on surgical-site infection. Br J Surg. 2011;98(7):1021-5

6. Holzer LA, Leithner A, Kazianschutz M, Gruber G. Noise measurement in total knee arthroplasty. Noise Health. 2014;16(71):205-7.

7. Tay BD, Prabhu IS, Cousin CH, Cousin GC. Occupational exposure to noise in maxillofacial operating theatres: an initial prospective study. Br J Oral Maxillofac Surg. 2015;

8. OSHA. OSHA Stanadard 29 CFR 1910.95. 2008. http://oshagov/pls/oshaweb/ owadispshow_document?p_table=STANDARDS\&pid $=9735$.

9. WHO. WHO guidelines for community noise. 1999. http://apps.who.int/iris/ handle/10665/66217.

10. Ginsberg SH, Pantin E, Kraidin J, Solina A, Panjwani S, Yang G. Noise levels in modern operating rooms during surgery. J Cardiothorac Vasc Anesth. 2013;27(3):528-30.

11. Tsiou C, Efthymiatos G, Katostaras T. Noise in the operating rooms of Greek hospitals. J Acoust Soc Am. 2008;123(2):757-65.

12. Kirschbaum C, Hellhammer DH. Noise and Stress - Salivary Cortisol as a Non-Invasive Measure of Allostatic Load. Noise Health. 1999;1(4):57-66.

13. Terlecki RP, Triest JA. A contemporary evaluation of the auditory hazard of extracorporeal shock wave lithotripsy. Urology. 2007;70(5):898-9.

Submit your next manuscript to BioMed Central and we will help you at every step:

- We accept pre-submission inquiries

- Our selector tool helps you to find the most relevant journal

- We provide round the clock customer support

- Convenient online submission

- Thorough peer review

- Inclusion in PubMed and all major indexing services

- Maximum visibility for your research

Submit your manuscript at www.biomedcentral.com/submit
Biomed Central 